\title{
pesquisa
}

NASCIMENTO, J.T.; PEDROSA, M.B.; TAVARES SOBRINHO, J. Efeito da variação de níveis de água disponível no solo sobre o crescimento e produção de feijão caupi, vagens e grãos verdes. Horticultura Brasileira, Brasília, v.22, n.2, p.174-177, abril-junho 2004.

\section{Efeito da variação de níveis de água disponível no solo sobre o cresci- mento e produção de feijão caupi, vagens e grãos verdes}

\author{
João Tavares Nascimento ${ }^{1,2}$; Murilo Barros Pedrosa ${ }^{2}$; José Tavares Sobrinho ${ }^{2}$ \\ ${ }^{1}$ Escola Agrotécnica Federal de Castanhal, Alameda Pe. Rolim, 124, 68743-580 Castanhal-PA; E-mail: jnascimenton@bol.com.br; \\ ${ }^{2}$ UFPB-CCA, C. Postal 02, 58397-000 Areia-PB
}

\section{RESUMO}

Estudou-se o efeito da variação de níveis de água disponível no solo, sobre o crescimento e produção de vagens e grãos verdes de feijão caupi [Vigna unguiculata (L.) Walp], cv. IPA 206. A produção de vagens e de grãos verdes desta espécie é uma excelente alternativa de comercialização para os agricultores do Nordeste do Brasil, visto que o seu consumo é bastante significativo na região. Instalouse o experimento em vasos de $13 \mathrm{~kg}$, em casa de vegetação na UFPB em Areia (PB), de agosto a dezembro de 2000 . O delineamento estatístico utilizado foi de blocos ao acaso com 4 tratamentos correspondentes aos níveis de água disponível do solo (40; 60; 80 e 100\%), logo após as irrigações, com 6 repetições. Os resultados observados mostraram que o nível crescente de déficit hídrico afetou drasticamente o desempenho desta cultivar em estudo em comparação à testemunha. As maiores reduções estimadas foram constatadas no comprimento da haste principal, 26 e $48 \%$, no número de folha por planta, 23 e $35 \%$, no número de vagens por planta, 32 e $49 \%$, e na massa de vagens por planta, 23 e $30 \%$, respectivamente para os níveis de 60 e $40 \%$ de água disponível do solo. Nas condições do experimento a cultivar de feijão caupi IPA 206 não tolera déficit hídrico acentuado.

Palavras-chave: Vigna unguiculata, déficit hídrico, feijão macassar, rendimento de grãos verdes.

\section{ABSTRACT}

Effect of different levels of available water in the soil on the growth and production of cowpea bean pods and green grains

The effect of different levels of available water in the soil was evaluated on the growth and production of green pod and green beans (Vigna unguiculata (L.) Walp) of cowpea, cv. IPA 206. Both forms of commercialization are excellent alternatives for farmers from the Northeast of Brazil. Plants were cultivated in $13 \mathrm{~kg}$ soil pots under green house conditions in Areia, Paraiba State, from August to December/2000. The experimental design was a randomized complete block design with six replications and four treatments corresponding to $40 ; 60 ; 80$ and $100 \%$ of available water in the soil, just after irrigations. The production was significantly affected by the deficit of water. Great reduction was observed in the length of the main stem ( 26 and $48 \%$ ), in the number of leaves per plant (23 and $35 \%$ ), in the number of pods per plant (32 and $49 \%$ ) and in the mass of pods per plant (23 and $30 \%$ ), respectively, for the levels of 60 and $40 \%$ of available water in the soil. The production of green pod and green beans of cowpea cv. IPA 206 is greatly affected by deficit of water of 40 and $60 \%$.

Keywords: Vigna unguiculata, deficit of water, macassar bean pod, green grains.

(Recebido para publicação em 15 de maio de 2003 e aceito em 4 de fevereiro de 2004)

$\mathrm{O}$ feijão caupi [Vigna unguiculata (L.) Walp], também conhecido como feijão macassar, representa fundamental importância social e econômica para o Nordeste do Brasil, constituindo-se como uma das principais fontes protéicas na alimentação da população rural (Embrapa, 1982). O consumo na forma de grãos secos, vagens ou grãos verdes como hortaliça, com 60 a 70\% de umidade (Oliveira et al., 2001), tem aumentado nos últimos anos, tornandose em excelente alternativa de comercialização para os agricultores.

No Estado da Paraíba é cultivado em quase todas as micro-regiões, onde detém $75 \%$ das áreas destinadas ao cultivo de feijão comum (IBGE, 1996). Nessas áreas, o cultivo de feijão caupi é realizado predominantemente sob o regime de sequeiro, onde a irregularidade de chuvas e altas temperaturas têm contribuído consideravelmente para o déficit hídrico e conseqüente redução da sua produtividade. Embora o feijão caupi seja considerado espécie adaptada à seca, sua capacidade de adaptação varia dentro da espécie (Turk e Hall, 1980; Ziska e Hall, 1982; Summerfield et al., 1985). Portanto, para o manejo adequado desta cultura, visando produtividade, é importante conhecer a capacidade de resposta aos níveis de déficit hídrico, bem como a relação entre consumo de água e produtividade. Com base nesse conhecimento, o agricultor pode selecionar cultivares apropriadas à situação. Costa et al. (1997) ressaltam a necessidade de avaliar o comportamento de cultivares desenvolvidas para sequeiro, para evitar perdas da produtividade.
Estudando os caracteres de adaptabilidade e estabilidade de vários genótipos de feijão caupi na região Semi-árida do Nordeste brasileiro, Santos et al. (2000) relataram que houve forte interação genótipo $\mathrm{x}$ ambiente, indicando desempenho distinto quando cultivados em diferentes situações de manejo e época do ano. Estes autores indicaram ainda, a possibilidade de explorar satisfatoriamente a interação genótipo $\mathrm{x}$ ambiente, com vista a recomendar-se genótipos com ampla ou específica adaptação, tanto para áreas de sequeiro, como para áreas irrigadas.

Leite et al. (1999) acrescentam a importância do conhecimento do crescimento da cultura em função da água disponível no solo, instrumento fundamental para explicar perdas de produ- 
ção em condições de déficit hídrico. A baixa produtividade desta cultura no estado da Paraíba, atribuída em parte à sua adaptação ecológica, mostra a necessidade do conhecimento do aproveitamento hídrico das cultivares usadas na região, visando melhor aproveitamento da água disponível no solo em combinação com a distribuição de chuvas.

A cultivar IPA 206 vem sendo cultivada e recomendada para o uso há dez anos na região; Entretanto, ainda são incipientes os resultados de pesquisa sobre sua adaptação na microrregião do Brejo Paraibano. Santos et al. (2000), estudando o comportamento produtivo desta cultivar em regime irrigado e de sequeiro, relataram alteração no seu comportamento quando da variação de água disponível no solo, com boa produtividade sob irrigação e, em regime de sequeiro, sua produção variou em função das oscilações pluviométricas.

Este trabalho teve por objetivo avaliar o efeito das variações de níveis de água disponível no solo sobre o crescimento e produção de feijão caupi, vagens e grãos verdes, var. IPA 206, a fim de se estabelecer o nível crítico de deficiência hídrica para esta cultivar no município de Areia (PB).

\section{MATERIAL E MÉTODOS}

O experimento foi conduzido em condições de casa de vegetação da UFPB em Areia, de agosto a dezembro de 2000, utilizando a cultivar de feijão caupi IPA 206.

$\mathrm{O}$ delineamento experimental empregado foi o de blocos ao acaso, com 4 tratamentos correspondentes aos níveis de água disponível (AD) de 40; 60; 80 e $100 \%$, mantido após as irrigações do solo, equivalendo aos níveis de umidade de 20; 30; 40 e $50 \mathrm{~g} \mathrm{~kg}^{-1}$, respectivamente, com 6 repetições, totalizando 24 parcelas.

O ensaio foi realizado em vasos plásticos de $13 \mathrm{~kg}$ de capacidade, em solo classificado como Neossolo Regolítico psamítico típico, de textura franco-arenosa, coletado na camada de $0-20 \mathrm{~cm}$, no qual se realizaram as análises físicohídrica e química em laboratório, com os resultados: areia grossa $=648 \mathrm{~g} \mathrm{~kg}^{-1}$; areia fina $=175 \mathrm{~g} \mathrm{~kg}^{-1}$; silte $=118 \mathrm{~g} \mathrm{~kg}^{-1}$; argila $=59 \mathrm{~g} \mathrm{~kg}^{-1}$; capacidade de campo para o potencial matricial de $-0,01 \mathrm{MPa}$ $(\mathrm{Cc})=89,1 \mathrm{~g} \mathrm{~kg}^{-1}$; ponto de murcha permanente para o potencial de $-0,1$ $(\mathrm{PMP})=39,1 \mathrm{~g} \mathrm{~kg}^{-1}$; água total disponí$\operatorname{vel}(A D)=50,0 \mathrm{~g} \mathrm{~kg}^{-1} ; \mathrm{pH}, 6,9 ; \mathrm{P}, 133$ $\mathrm{mg} \mathrm{dm}{ }^{-3} ; \mathrm{K}^{+}, 110 \mathrm{mg} \mathrm{dm}{ }^{-3} ; \mathrm{Na}^{+}, 0,21$ $\mathrm{cmol}_{\mathrm{c}} \mathrm{dm}^{-3} ; \mathrm{H}^{+}+\mathrm{Al}^{3+}, 0,58 \mathrm{cmol}_{\mathrm{c}} \mathrm{dm}^{-3}$; $\mathrm{Ca}^{++}+\mathrm{Mg}^{++}, 5,10 \mathrm{cmol}_{\mathrm{c}} \mathrm{dm}^{-3}$.

A adubação mineral recomendada para a cultura do feijão caupi em função da análise química do solo foi de 30 $\mathrm{kg}$ de N/ha, $60 \mathrm{~kg}$ de $\mathrm{P}_{2} \mathrm{O}_{5} /$ ha e $60 \mathrm{~kg}$ de $\mathrm{K}_{2} \mathrm{O} /$ ha, usando o sulfato de amônio (1 $\mathrm{g} /$ vaso), superfosfato simples ( $2 \mathrm{~g}$ /vaso) e o cloreto de potássio ( $0,65 \mathrm{~g} / \mathrm{vaso})$, como fontes de N, P e K, respectivamente. O sulfato de amônio foi aplicado em duas vezes, sendo a metade aos 20 dias da emergência, e a outra, aos 40 dias. O total de superfosfato simples e o do cloreto de potássio foram aplicados no plantio. A semeadura foi realizada nos vasos com a distribuição de 4 sementes e aos 7 dias da emergência, realizou-se o desbaste, deixando a planta mais vigorosa.

Durante 15 dias após a emergência (DAE), a umidade do solo foi mantida no nível de $100 \%$ da água disponível (AD). A partir deste período, as irrigações foram feitas considerando os níveis de 40; 60; 80 e 100\% AD, durante a fase vegetativa à colheita final. $\mathrm{O}$ controle da irrigação determinado pelos tratamentos, foi feito diariamente através do método de pesagem e a quantidade de água consumida foi reposta de modo a manter cada tratamento com o nível de água do solo previamente estabelecido, realizado sempre no intervalo das 7;00 às $8 ; 00 \mathrm{~h}$.

Os componentes de produção avaliados foram: número de grãos por vagem (NGV), número de vagens por planta (NVP), massa de grãos por planta (MGP), massa de vagens por planta (MVP) e comprimento médio de vagens por planta (CMV). Para a análise de crescimento, foram avaliados os componentes: comprimento da haste principal (CHP) e o número de folhas por planta (NFP).

A avaliação dos componentes de produção foi realizada no momento da colheita das vagens, quando estas atingiam a fase de maturação não comple- ta, ou seja, no estágio de vagens ou grãos verdes na faixa de 60 a $70 \%$ de umidade (Oliveira et al. 2001). Para a avaliação de crescimento, as mensurações foram obtidas do $22^{\circ}$ ao $43^{\circ} \mathrm{DAE}$, em intervalos de 7 dias, compreendendo parte da fase vegetativa e início da reprodutiva. Os dados utilizados para análise de variância do comprimento da haste principal (CHP) e do número de folhas por planta (NFP) foram os obtidos na ultima avaliação, aos 43 DAE.

Os dados obtidos foram submetidos à análise variância e de regressão para explicar o comportamento dos componentes estudados em função dos tratamentos aplicados.

\section{RESULTADOS E DISCUSSÃO}

Houve diferenças significativas $(\mathrm{P}<0,01)$ entre os tratamentos (níveis de água disponível no solo) para todos os componentes avaliados, indicando que os níveis de deficiência hídrica aplicados no solo, influenciaram significativamente o desempenho do crescimento de plantas e de produção de feijão caupi, cv. IPA 206.

Na Figura 1 (a) e (b) está representada a variação da evolução do CHP e do NFP, respectivamente, sob os níveis de $40 ; 60 ; 80$ e $100 \%$ AD, mensurado no período do $22^{\circ}$ ao $43^{\circ}$ DAE, correspondente à fase vegetativa e início da reprodutiva. Para estas variáveis $(\mathrm{CHP}$ e NFP), observou-se comportamento semelhante entre tratamentos até aos 29 DAE, quando então, a partir deste período se iniciou a diferenciação entre eles, acentuando-se com a aproximação da fase reprodutiva aos 43 DAE. Analisando os comportamentos através dos dados, verificaram-se efeitos extremamente negativos, sendo crítico para os níveis de 60 e $40 \% \mathrm{AD}$, ocorridos a partir da pré-floração. Com isto, evidenciase claramente que a exigência por esta cultura em água aumenta com a proximidade da fase reprodutiva, denotandose que esta cultivar em estudo é mais tolerante ao déficit hídrico na fase vegetativa. Estes resultados são concordantes com os de Leite et al. (1999), quando relataram que os efeitos de déficits hídricos ocorridos na fase vegetativa do caupi provocaram meno- 
res reduções nos componentes de crescimento, porém, na fase reprodutiva, ou seja, na pré-floração e no enchimento de grãos, seus efeitos foram mais acentuados.

Os dados dessas variáveis (CHP e NFP) obtidos aos 43 DAE foram submetidos à análise de regressão, a qual constatou efeito quadrático para o $\mathrm{CHP}$ $\left(\mathrm{Y}=11,549+2,1729 \mathrm{x}-0,0086 \mathrm{x}^{2}\right.$; $\left.\mathrm{R}^{2}=0,99 * *\right)$ e linear para o NFP $\left(\mathrm{Y}=3,8334+0,0542 \mathrm{x} ; \mathrm{R}^{2}=0,99 * *\right)$. Pelos resultados estimados pelas equações, observaram-se reduções de aproximadamente $10 ; 26$ e $48 \%$ e $11 ; 23$ e $35 \%$, para o CHP e NFP, respectivamente, para os níveis de $80 ; 60$ e $40 \% \mathrm{AD}$, quando comparados à testemunha. Portanto, dos resultados entre variáveis, verificou-se valores aproximados e crescentes com os níveis de déficit hídrico nas faixas de 80 e $60 \% \mathrm{AD}$, sendo que no nível de $40 \%$, o efeito redutivo foi em maior magnitude e mais acentuado para o CHP.

Resende et al. (1981) relataram que plantas submetidas a tensões hídricas reduzem a turgescência e, conseqüentemente, a expansão celular, o que promove redução no alongamento do caule e da folha. Para Babalola (1980), a translocação de fotoassimilados para as raízes é comprometida em condições de déficit hídrico, afetando diretamente o crescimento das plantas. Já, para Leite et al. (1999), considerando que as folhas são os centros de produção da fotossíntese e que o resto da planta depende da exportação de material assimilado da folha para outros órgãos da planta de feijão caupi, o estresse hídrico nesta cultura, compromete tal exportação, contribuindo para os decréscimos de seu crescimento e produção. Resultados semelhantes foram relatados por TurK e Hall (1980) e Hiler et al. (1972), quando plantas de feijão caupi submetidas à deficiência hídrica apresentaram baixa transpiração, refletindo na redução de altura de plantas. Távora e Melo (1991), estudando o amendoim submetido a ciclos de deficiência hídrica, constataram também reduções significativas do número de folhas por planta. Ainda, Larcher (1986) afirma que, pela deficiência de água, ocorre perda progressiva da turgescência protoplasmática e

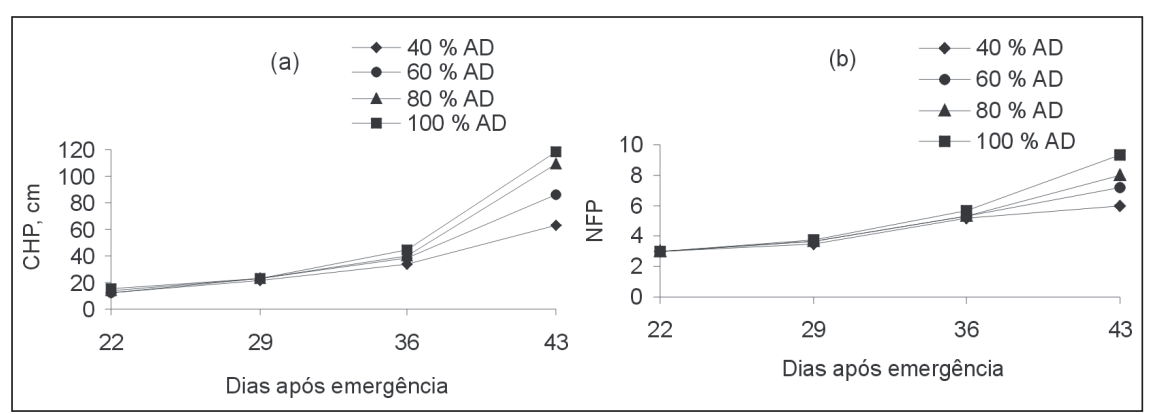

Figura 1. (a) CHP, comprimento da haste principal, e (b) NFP, número de folhas por planta, em feijão caupi cv. IPA 206, cultivado sob níveis de água disponível no solo. Areia, UFPB, 2000.

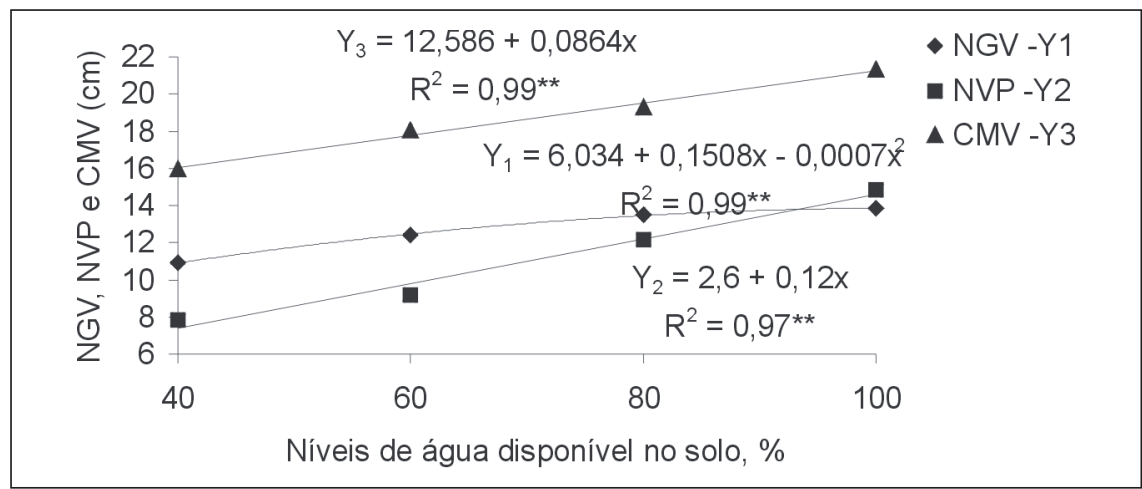

Figura 2. Número de grãos por vagem, $\mathrm{NGV}\left(\mathrm{Y}_{1}\right)$, número de vagens por planta, $\mathrm{NVP}\left(\mathrm{Y}_{2}\right)$ e comprimento médio de vagens por planta, $\mathrm{CMV}\left(\mathrm{Y}_{3}\right)$, em feijão caupi cv. IPA 206, cultivado sob níveis de água disponível no solo. Areia, UFPB, 2000.

aumento na concentração de solutos. Dos efeitos destes, resulta inicialmente um distúrbio na função celular. Surgem, então, os déficits funcionais e, por fim, as estruturas protoplasmáticas são danificadas. Segundo ainda este mesmo autor, a redução da perda de água, pela redução da superfície de transpiração da planta, para evitar a sua dessecação, parece ser uma das medidas comportamentais, entre outras, de resistência ao déficit hídrico, refletindo-se na sua morfologia. A redução da superfície de transpiração é efetuada rápida e reversivelmente, pelo desdobramento e enrolamento das folhas. Esta ocorrência também foi constatada para esta cultivar em estudo, principalmente, nos tratamentos nos níveis de 60 e $40 \%$ de água disponível no solo.

Para os componentes de produção da cultivar em estudo (Figura 2), a variação encontra-se representada pelas seguintes equações de regressão: efeito quadrático para o NGV $\left(\mathrm{Y}_{1}\right)$ e efeito linear para o NVP $\left(\mathrm{Y}_{2}\right)$ e $\mathrm{CMV}\left(\mathrm{Y}_{3}\right)$. Nos valores estimados pelas equações, relativo à testemunha foram observados decréscimos crescentes com o aumento do déficit hídrico, sendo para o NGV, decréscimos de aproximadamente 3; 9 e $22 \%$, e para o NVP, reduções da ordem de aproximadamente, 16; 32 e 49\%, enquanto para o CMV, reduções de aproximadamente, $8 ; 16$ e $24 \%$, referentes aos níveis de $80 ; 60$ e $40 \% \mathrm{AD}$, respectivamente para esses componentes.

Para o componente MGP (Figura 3 a), verificou-se comportamento linear, e comportamento quadrático para a MVP (Figura 3 b). Nos resultados estimados, observou-se decréscimos de produção relativa à testemunha de aproximadamente, 3; 8 e 13\% para MGV, e para MVP, também reduções da ordem de 13; 23 e $30 \%$, relativos aos níveis de $80 ; 60$ e $40 \% \mathrm{AD}$, respectivamente para ambos os componentes.

De maneira geral, considerando estes resultados, verifica-se através das equações de regressão estudadas para os componentes de produção nas Figuras 2 e 3, grande variação da produção desta cultivar em estudo, frente às deficiências hídricas impostas pelos tratamentos, com reduções significativas, à medida que diminuíram os níveis de água disponível no solo, sendo considerados 


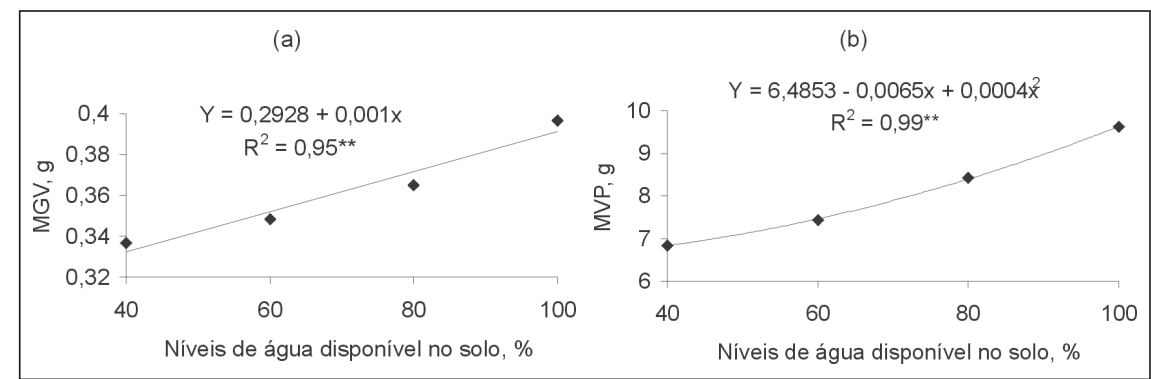

Figura 3. (a) MGV, massa de grãos por vagem, e (b) MVP, massa de vagens por planta, em feijão caupi cv. IPA 206, cultivado sob níveis de água disponível no solo. Areia, UFPB, 2000.

críticos para esta cultivar, os níveis de 60 e $40 \%$.

O componente NVP foi grandemente afetado pelos níveis de estresse hídrico e com mais severidade que o ocorrido nos outros componentes, em todos os níveis de déficit hídrico impostos pelos tratamentos. Segundo Leite et al. (2000), tal comportamento pode ser explicado como um dos mecanismos de resistência à seca utilizado por esta planta, no sentido de buscar melhores condições para superar a falta de água, produzindo menor quantidade de vagens. Por sua vez, Lima (1996), avaliando o efeito de cinco níveis de água disponível no crescimento e produtividade do feijão caupi, observou também que o número de vagens por planta diminuiu com o aumento do estresse hídrico. Para este autor, a redução deste componente parece ser o principal fator de decréscimos na produção de grãos de feijão caupi. Miranda e Belmar (1977) e Stone et al. (1988) também observaram redução no número de vagens por planta em feijoeiros submetidos à deficiência hídrica. Summerfield et al. (1976), encontrou no caupi redução de 50\% no número de vagens e massa de grãos por planta quando o estresse hídrico foi imposto na fase de desenvolvimento vegetativo.

De acordo com Karamanos et al. (1982), a ocorrência de estresse hídrico durante a fase vegetativa inicial, provoca redução do crescimento e da superfície fotossintética, ocorrendo conseqüentemente, menor número de flores, de vagens por planta e de grãos por vagens. Carvalho et al. (2000), por sua vez, constataram queda na produção de 32 a $100 \%$, relativos aos níveis de 80 e $20 \%$ de água consumida, respectivamente, em relação à testemunha (reposição de $100 \%$ de água consumida). Ritchie
(1981) afirma que além de afetar a expansão foliar, a deficiência hídrica do solo pode causar o enrolamento e a abscisão, ou morte parcial das folhas, diminuição da brotação, polinização, translocação e enchimento de grãos, bem como, o abortamento das vagens.

Para esta cultivar em estudo, IPA 206, os níveis de água disponível no solo de 40 e $60 \%$, exerceram efeitos extremamente negativos sobre os componentes de produção, especialmente sobre o número de vagens por planta com mais severidade, evidenciando-se ser este um mecanismo importante de resistência à seca.

\section{AGRADECIMENTOS}

Os autores agradecem ao Prof. Dr. Genildo Bandeira Bruno, Coordenador do Programa de Pós-Graduação em concedido para a realização deste experimento.

\section{LITERATURA CITADA}

BABALOLA, O. Water relations of three cowpea cultivars [Vigna unguiculata (L.) Walp]. Plant and Soil, v.56, p.59-69, 1980.

CARVALHO, J.A.; PEREIRA, G.M.; ANDRADE, M.J.B.; ROQUE, M.W. Efeito do déficit hídrico sobre o rendimento do feijão caupi [Vigna unguiculata (L.) Walp]. Ciênc. Agrotec., Lavras, v.24, n.3, p.710-717, 2000.

COSTA, M.M.M.N.; TÁVORA, F.J.A.F.; PINHO, J.L.N.; MELO, F.I.O. Produção, componentes de produção, crescimento e distribuição das raízes de caupi submetido à deficiência hídrica. Pesquisa Agropecuária Brasileira, Brasília, v.32, n.1, p.4350, 1997.

EMPRESA BRASILEIRA DE PESQUISA AGROPECUÁRIA. CNP-Arroz e Feijão Promove Reunião e Cursos sobre o Cultivo da Cultura do Caupi. Brasília: 46-82, 1982. (EMBRAPACNPAF. Informativo, 9)

HILER, E.A.; VAN BAVEL, C.H.M.; HOSSAIN, M.M.; JORDAN, W.R. Sensitivity of southern peas to plant water deficit at three growth stages Agron. J., v.64, p.60-64, 1972. Agronomia do CCA-UFPB, pelo apoio
IBGE. Instituto Brasileiro de Geografia e Estatística. Anuário estatístico. Rio de Janeiro, 1996. KARAMANOS, A.J.; ELSTON, J.; WADSWORTH, R.M. Water stress and leaf growth of field beans (Vicia faba, L.) in the field: water potentials and laminar expansion. Annals of Botany, v.49, n.6, p.815-826, 1982.

LARCHER, W. Ecofisiologia vegetal. 4 ed. São Paulo: EPU. 1986, 339 p.

LEITE, M.L.; RODRIGUES, J.D.; MISCHAN, M.M.; VIRGENS FILHO, J.S. Efeitos do déficit hídrico sobre a cultura do caupi [Vigna unguiculata (L.) Walp], cv. EMAPA-821. II - Análise de Crescimento. Rev. de Agricultura. Piracicaba, v.74, n.3, p.351-370, 1999.

LEITE, M.L.; RODRIGUES, J.D.; VIRGENS FILHO, J.S. Efeitos do déficit hídrico sobre a cultura do caupi, cv. EMAPA-821. III - Produção. Rev. de Agricultura. Piracicaba, v.75, n.1, p.9-20, 2000.

LIMA, G.P.B. Crescimento e produtividade do caupi [Vigna unguiculata (L.) Walp] sob diferentes níveis de disponibilidade hídrica do solo. In: REUNIÃO NACIONAL DE PESQUISA DE CAUPI, 4., 1996, Teresina. Resumos... Teresina: CNPAMN/ EMBRAPA, 1996. p.41-43.

MIRANDA, N.O.; BELMAR, N.C. Déficit hídrico y frecuencia de riego en frijol (Phaseolus vulgaris L.). Agricultura Técnica, v.37, n.3, p.111117, 1977.

OLIVEIRA, A.P.; ARAÚJO, J.S.; ALVES, E.U.; NORONHA, M.A.S.; CASSIMIRO, C.M.; MENDONÇA, F.G. Rendimento de feijão caupi cultivado com esterco bovino e adubo mineral. Horticultura Brasileira. Brasília, v.19, n.1, p.81-84, 2001.

RESENDE, M.; HENDERSON, D.W. FERERES, E. Freqüência de irrigação e produção de feijão Kidney. Pesquisa Agropecuária Bras., Brasília, v.16, n.3, p.363-370, 1981.

RITCHIE, J.T. Water dynamics in the soil-plantatmosphere system. Plant and Soil, v.58, p.81-96, 1981.

SANTOS, C.A.F.; ARAÚJO, F.P.; MENEZES, E.A. Comportamento produtivo de caupi em regime irrigado e de sequeiro em Petrolina e Juazeiro. Pesquisa Agropecuária Brasileira, Brasília, v.35, n.11, p.2229-2234, 2000.

STONE, L.F.; MOREIRA, J.A.A.; SILVA, S.C. Efeitos da tensão da água do solo sobre a produtividade e crescimento do feijoeiro. I. Produtividade. Pesquisa Agropecuária Brasileira, Brasília, v.23, n.2, p.161-167, 1988.

SUMMERFIELD, R.J.; HUXLEY, P.A.; DART, P.J.; HUGHES, A.P. Some effects of environmental stress on seed yield of cowpea. Plant and Soil, v.44, p.527-546, 1976.

SUMMERFIELD, R.J.; PATE, J.S.; ROBERTS, E.H.; WIEN, H.C. The physiology cowpea. In: SINGH, S.R.; RACHIE, K.O. (Eds.). Cowpea research, production and utilization. Chichester: John Wiley, 1985. p.66-101.

TÁVORA, F.J.A.F.; MELO, F.I.O. Respostas de cultivares de amendoim a ciclos de deficiência hídrica: crescimento vegetativo, reprodutivo e relações hídricas. Ciência Agronômica, Fortaleza, v.22, n.1/2, p.47-60, 1991.

TURK, K.J.; HALL, A.E. Drougth adaptation of cowpea. III. Influence of drougth on plant growth and relations with seed yield. Agonomy Journal, v.72, p.428-433, 1980.

ZISKA, L.H.; HALL, A.E. Seed yields and water use of cowpeas [Vigna unguiculata (L.) Walp] subjected to planned-water deficit irrigation. Irrigation Science, v.3, p.1-9, 1982. 